Sustainability, Agri, Food and Environmental Research, (ISSN: 0719-3726), 10(X), 2022:

http://dx.doi.org/

\title{
Strength analysis of soil blocks admixed with sugarcane
} bagasse ash.

\section{Análisis de resistencia de bloques de suelo mezclados con ceniza de bagazo de caña de azúcar.}

\author{
${ }^{1}$ Shwetha Prasanna, Swaroopa Sail, ${ }^{3}$ Rhea Patil, ${ }^{4}$ Maryann De Souza, ${ }^{5}$ Anushuka \\ Prasad, ${ }^{6}$ Aakash Gavandalkar, ${ }^{7}$ Yatish Gaude, Students
}

\begin{abstract}
1 Associate Professor, ${ }^{2}$ Assistant Professor, 4,5,6,7 Students, Don Bosco College of Engineering, Fatorda, Goa, India.
\end{abstract}

Emails: Shwetha Prasanna (shwethaprasanna@gmail.com); Swaroopa Sail: (swaroopasail@gmail.com); Rhea Patil (rheapatil22@gmail.com); Maryann De Souza (marydesouza0832@gmail.com); Anushuka Prasad (anushuka.p22@gmail.com); Aakash Gavandalkar (gavandalkaraakash@gmail.com); Gatish Gaude (yatishgaude21664@gmail.com)

ABSTRACT

This paper is mainly focusing on the stabilization of soil using sugarcane baggase ash (SBA) as a soil stabilizer. The locally available soil samples were collected and their properties were determined. Based on the laboratory test results the soil was classified as fine-grained soil. Soil stabilized blocks of dimensions $15 \mathrm{~cm} \times 15 \mathrm{~cm} \times 15 \mathrm{~cm}$ were prepared with the following soil, cement and SBA combinations $100 \%$ soil, $80 \%$ soil $+20 \%$ cement, $80 \%$ soil $+10 \%$ cement $+10 \%$ SBA, $80 \%$ soil $+8 \%$ cement $+12 \%$ SBA and $80 \%$ soil $+6 \%$ cement $+14 \%$ SBA. Plain OPC cement of 43 grade and SBA from sugar factory Goa was used for the soil blocks. The blocks were moist cured for a period of 28 days. The soil stabilized blocks were then tested for their compressive strength under the universal testing machine according to BIS specifications. The effects of the SBA on the strength of the soil blocks were studied and it could be concluded that SBA can be used as a partial replacement of cement.

Key words: sugarcane bagasse ash, compressive Strength, soil stabilized block, cement.

\section{RESUMEN}

Este artículo se centra principalmente en la estabilización del suelo utilizando ceniza 
Sustainability, Agri, Food and Environmental Research, (ISSN: 0719-3726), 10(X), 2022:

http://dx.doi.org/

de bolsa de caña de azúcar (SBA) como estabilizador del suelo. Se recolectaron las muestras de suelo disponibles localmente y se determinaron sus propiedades. Según los resultados de las pruebas de laboratorio, el suelo se clasificó como suelo de grano fino. Se prepararon bloques de suelo estabilizado de dimensiones $15 \mathrm{~cm} \times 15 \mathrm{~cm} \times 15 \mathrm{~cm}$ con las siguientes combinaciones de suelo, cemento y SBA $100 \%$ suelo, $80 \%$ suelo $+20 \%$ cemento, $80 \%$ suelo $+10 \%$ cemento $+10 \%$ SBA, $80 \%$ suelo $+8 \%$ cemento $+12 \%$ SBA y $80 \%$ suelo $+6 \%$ cemento $+14 \%$ SBA. Para los bloques de suelo se utilizó cemento OPC simple de grado 43 y SBA de la fábrica de azúcar de Goa. Los bloques se curaron en húmedo durante un período de 28 días. Luego, los bloques estabilizados con suelo se probaron para determinar su resistencia a la compresión bajo la máquina de prueba universal de acuerdo con las especificaciones de BIS. Se estudiaron los efectos del SBA sobre la resistencia de los bloques de suelo y se pudo concluir que el SBA puede utilizarse como reemplazo parcial del cemento.

Palabras clave: ceniza de bagazo de caña de azúcar, resistencia a la compresión, bloque estabilizado de suelo, cemento.

\section{INTRODUCTION}

Soil has been used everywhere as a major building material in the form of mud, sawmill and brick for centuries. However, when used in any form other than burnt bricks, such structures are short-lived as they become easily lost in contact with water. The stabilization is the option for improving soil properties and to make it suitable for permanent buildings material. Cement is one of the binding materials can be is used in soil stabilization. When a small amount of cement about $1-10 \%$ is added into the soil and then compressed mechanically to make building blocks, the resultant blocks are water resistant and their compressive strength highly increased making it strong enough to build buildings. Because of rapid infrastructure development use of cement, lime and other chemical admixtures for soil stabilization has increased over the years. All this has started to have adverse effect on the environment that has led to its degradation. Cement manufacture contributes greenhouse gases directly through the production of carbon dioxide when calcium carbonate is thermally decomposed, producing lime and carbon dioxide, and also through the use of energy, particularly from the combustion of fossil fuels. Hence nowadays engineers have directed their approach from using chemicals that harm or destroy the environment to materials that are eco-friendly and also equally as good as those chemicals. Stabilized soil blocks (SSBs) are building blocks most of the times made from ordinary soil mixed with a small amount of cement and water. They are highly compacted, resulting in a low cost solid and building block. 
Sustainability, Agri, Food and Environmental Research, (ISSN: 0719-3726), 10(X), 2022: http://dx.doi.org/

So when these soil stabilized blocks are admixed with agricultural or industrial wastes they tend to enhance the block properties and also reduce the concerning issues of affecting the environment. Agricultural wastes like wheat straw ash, rice husk ash, hazel nutshell and sugar cane bagasse ash (SBA) contribute for the development of concrete by acting as pozzolanic materials.

The effects of bagasse ash content as partial replacement of cement on physical and mechanical properties of hardened concrete was studied in a paper authored by Ganesan (Ganesan,K., et.al,2007). Their test results concluded that bagasse ash can be used as an is an effective mineral admixture, with $20 \%$ as optimal replacement ratio of cement. Bio-fuel by- product sugarcane bagasse ash (SBA) was used as an effective raw material for the manufacturing of bricks in one of the papers studied by authors Mangesh et al., (2014), Sachin and Rahul Ralegaonkar. The bricks were made using quarry dust (QD) to replace natural river sand and lime $(\mathrm{L})$ as a binder. Authors also studied physio-mechanical properties of the developed bricks according to recommended standards. They concluded that bricks could be used in local construction especially for non-load-bearing walls. Onchiri et.al 2017 worked on the use of sugarcane bagasse ash as a partial replacement for cement to stabilize self-interlocking compressed earth blocks (SSIEBs) using various bagasse ash contents for replacement of cement. Ordinary Portland cement Zuari-53 grade conforming to IS: $12269-$ 1987 was used in concrete. A crushed granite rock with a maximum size of $20 \mathrm{~mm}$ having specific gravity of 2.74 was used as a coarse aggregate. Bagasse ash was burnt for approximately 3 days in air in an uncontrolled burning process. The bagasse ash was used in different percentages like $0 \%, 5 \%, 10 \%, 15 \%$ and $20 \%$. The study showed that sugarcane bagasse ash can effectively use as a replacement for cement (up to 10\%) with considerable change in strength. Jijo James, ) studied the performance of ordinary Portland cement (OPC) stabilized soil blocks amended with sugarcane bagasse ash (SBA). Locally available soil was tested for its properties and characterized as clay of medium plasticity. The results were addition of SBA increased the compressive strength of the blocks and slightly increased the water absorption but still met the standard requirement of BIS code. It was concluded that addition of SBA to OPC in stabilized block manufacture was capable of producing stabilized blocks at reduced OPC content that met the minimum required standards. Abd Halid Abdullah (Halid et.al,2017) in his study, he considered 1:10 (cement: soil) mix proportion ratio of laterite soil and clay types for producing compressed stabilized earth block (CSEB) prototypes. This study showed that the increase in compression pressure would result in different strength for both CSEBs made from laterite soil and clay. A comprehensive review of the state-of-the art morphology, physical properties, chemical composition, and mineralogical composition of 
Sustainability, Agri, Food and Environmental Research, (ISSN: 0719-3726), 10(X), 2022:

http://dx.doi.org/

SBA was done by Qing Xu, (Qing Xu et.al,2019). Their studies showed that SBA is an effective and potentially promising construction material. Due to the high amount of amorphous or partially crystalline silica and amorphous alumina, SBA can be used as a pozzolanic material. Authors also investigated the possibility of using SBA to stabilize lateritic soil and found that SBA cannot be used as a stabilizer alone and must be used with adequate cement stabilization. In the present study authors have utilized SBA, the waste from sugar industry to stabilize soil blocks.

\section{MATERIALS AND METHODS}

The soil samples used in this study were obtained from Nuvem site, Goa India. The collected soil sample was found to be fine grained after carrying out particle size distribution test (wet sieve analysis). The soil samples were subjected to different laboratory tests such as Particle size distribution, Specific gravity test, Hydrometer test and Moisture content. The following results were found.

Table 1 properties of soil

\begin{tabular}{cl}
\hline Property & Value \\
\hline Specific gravity & 2.63 \\
Moisture content & $13 \%$ \\
Percentage of gravel & $17.6 \%$ \\
Percentage of Sand & $26.8 \%$ \\
Percentage of fine-grained soil & $55.6 \%$ \\
Percentage of Silt & $52 \%$ \\
\hline Percentage of Clay & $4 \%$ \\
\hline
\end{tabular}

After conducting the sieve analysis test on soil it was found that the soil contains silt and clay more and based on that it is classified as fine grained soil. From the calculations the percentage of fine grained soil is more than $50 \%$. Hence hydrometer test was conducted to check whether the soil is silt or clay. The Sugarcane bagasse ash was brought from Sanjivani Sugar Factory, Piliem, Goa and was ground to 300 microns. One of the authors in their paper (Balakrishnan \& V. S. Batra,2011) mentioned that the major solid wastes generated from the sugar manufacturing process include sugarcane trash, bagasse, press mud, bagasse flyash. Bagasse is the fibrous material remains from the cane after extraction of sugarcane juice. In many industries, bagasse is used as fuel resulting in the generation of ash called SBA. SBA is one of the wastes of economic importance generated from the sugar industry, as it has lots 
Sustainability, Agri, Food and Environmental Research, (ISSN: 0719-3726), 10(X), 2022:

http://dx.doi.org/

of potential uses. SBA has been used in the manufacture of low cost adsorbents, in ceramics, in concrete, in soil stabilization, and recently in stabilized earth blocks.

The detail study was conducted for the preparation and characterization of materials, selection of soil block size, selection of stabilizer and additive content, mould fabrication, casting and curing of blocks etc. As per BIS code there are three sizes of cement stabilized soil blocks of dimensions, $19 \times 9 \times 4,19 \times 9 \times 9$ and $29 \times 19 \times 9$, all dimensions are in $\mathrm{cm}$. The block dimension adopted in this study was $15 \mathrm{~cm} \times 15 \mathrm{~cm} \times 15 \mathrm{~cm}$. The same methodology which is generally used in casting the soil blocks was implemented here also to preparee the unconfined compression blocks for testing soil specimens. The soil blocks were casted for the density of $1.5 \mathrm{~g} / \mathrm{m}^{3}$ and a moisture content of $12.76 \%$. The mould was prepared by tightening all the bolts. The oil was applied for the interior surface and properly lubricated for easy removal of the pressed block. The weights of soil, cement, and SBA were measured carefully and mixed thoroughly in dry conditions. Measured required quantity of water and added to the mixture, and mixed thoroughly to get an even wet mix. The wet mix was then placed in the mould, and followed by the top plate and a compression test ram was used to press the top plate. The mould was so designed that the top plate cannot be lowered below the fixed dimensions of the block. Completely pressing the entire mix in the mould resulted in achieving more or less uniform density of blocks for testing. The mould was opened after the formation of the block, and the block was removed and was moisture-cured for a period of 28 days by sprinkling of water and covering with plastic gunny bags to prevent loss of moisture. Figure 3 shows the preparation of stabilized blocks.

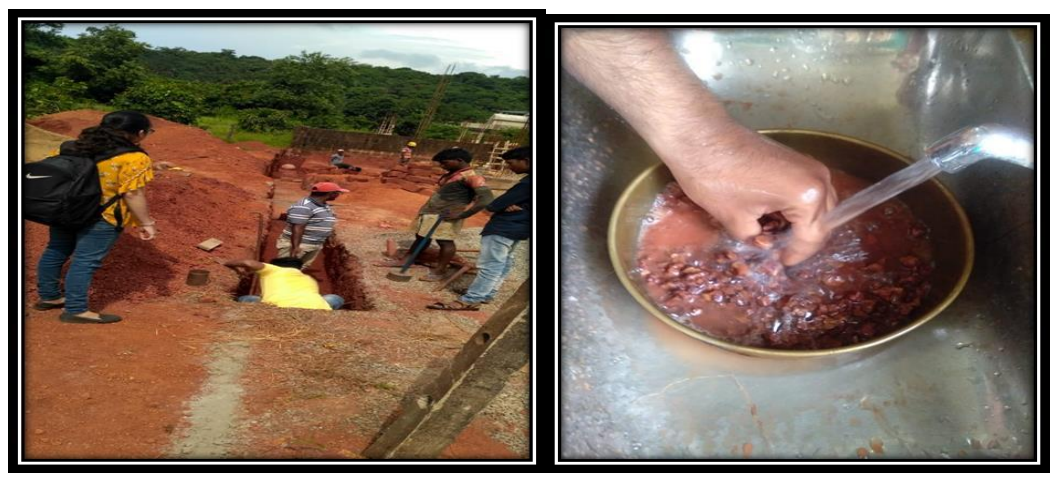

Fig. 1: Collection and washing of soil sample 
Sustainability, Agri, Food and Environmental Research, (ISSN: 0719-3726), 10(X), 2022:

http://dx.doi.org/

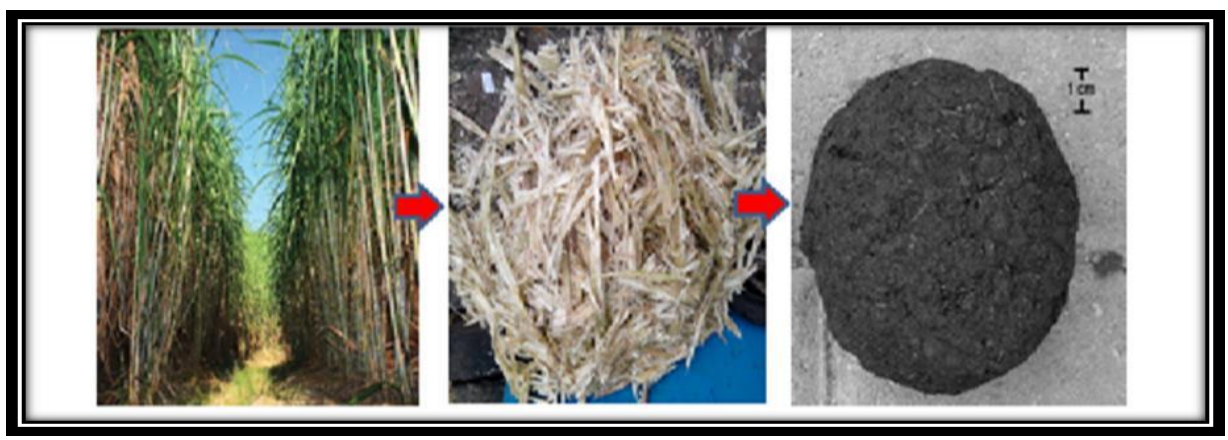

Fig. 2: Sugarcane, sugarcane bagasse and bagasse ash

BIS code recommends that a stabilized soil block should meet the compressive strength, water absorption, and weathering resistance requirements. In this present study the stabilized soil blocks were subjected to only compressive strength, did not carry out any tests on water absorption, and weathering resistance requirements. The test was conducted according to BIS specifications. Three blocks were tested for all combinations and the average value was taken as the result for the particular combination for the test. Different soil blocks were casted with the following combinations of soil, cement and SBA.

Table 2. Different combinations of soil, cement \& sba

\begin{tabular}{cccc}
\hline SR. NO. & $\begin{array}{c}\text { SOIL } \\
(\mathrm{kg})\end{array}$ & $\begin{array}{c}\text { CEMENT } \\
(\mathrm{kg})\end{array}$ & $\begin{array}{c}\text { SBA } \\
(\mathrm{kg})\end{array}$ \\
\hline 1 & $100 \%$ & --0 & --0 \\
& 17 & & \\
2 & $80 \%$ & $20 \%$ & -- \\
& 13.6 & 3.4 & 0 \\
3 & $80 \%$ & $10 \%$ & $10 \%$ \\
& 13.6 & 1.7 & 1.7 \\
4 & $80 \%$ & $8 \%$ & $12 \%$ \\
& 13.6 & 1.36 & 2.04 \\
\hline 5 & $80 \%$ & $6 \%$ & $14 \%$ \\
& 13.6 & 1.02 & 2.36 \\
\hline
\end{tabular}

In first trial blocks were prepared using only soil (100\%). In second trial $80 \%$ of soil and $20 \%$ of cement were used. In third trial $80 \%$ of soil, $10 \%$ of cement and $10 \%$ of SBA 
Sustainability, Agri, Food and Environmental Research, (ISSN: 0719-3726), 10(X), 2022: http://dx.doi.org/

were used. In fourth trail $80 \%$ of soil, $8 \%$ of cement and $12 \%$ of SBA were used. In the last trial $80 \%$ of soil, $6 \%$ of cement and $14 \%$ of SBA were used.

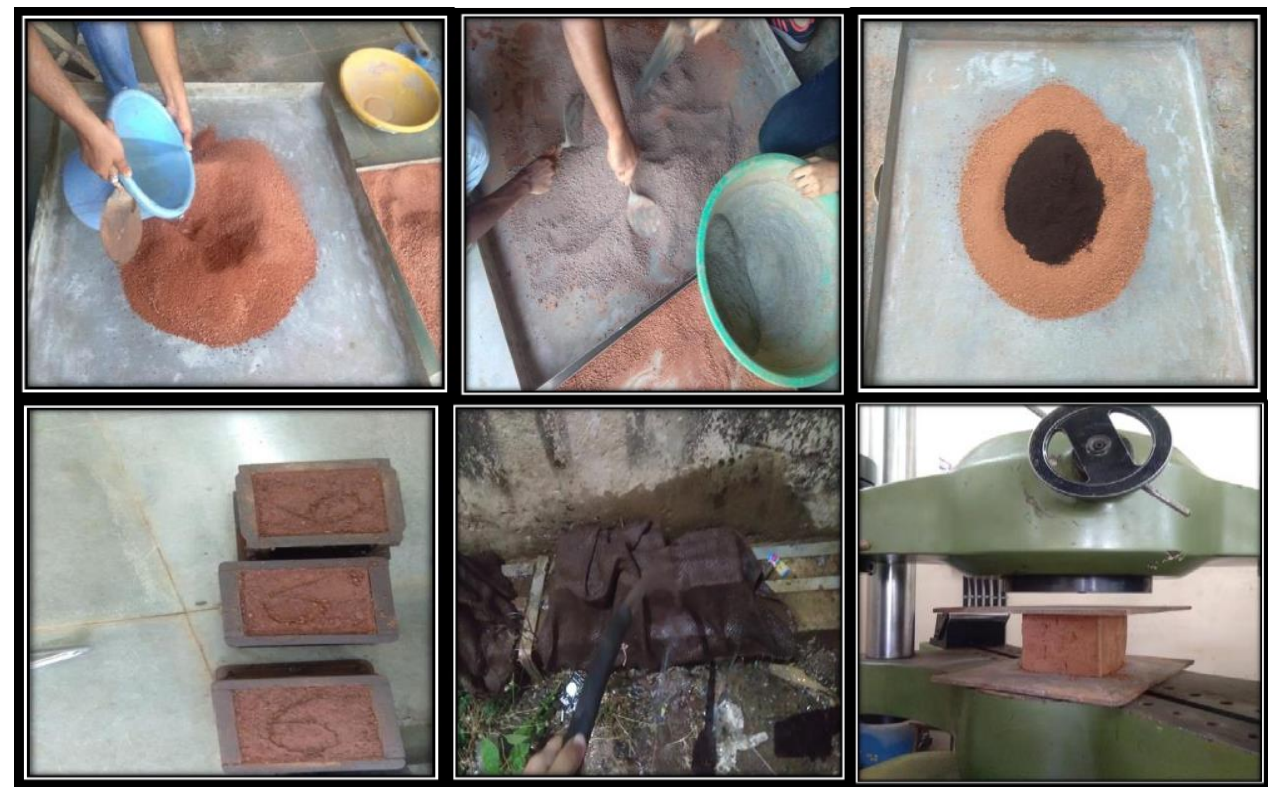

Fig. 3: Preparation of stabilized soil blocks

\section{RESULTS AND DISCUSSION}

Compression test was carried out for all the above-mentioned combinations of soil blocks and the following results were obtained. As per BIS code specifications, the compression test on the stabilized soil blocks was carried out. It can be seen in Table 2, that the addition of SBA, results an in increase in strength of the stabilized soil block. Authors Greepala \&. Parichartpreecha, (2011); Khobklang et al, (2008) in their study they found that increasing SBA content addition to cement stabilized lateritic soil with sand resulted in a decreasing strength at 28 days of curing. But the trends were different for 90 days of curing. For the addition of $12 \%$ SBA, the strength of the soil block steadily increases and reaches a maximum of $1.02 \mathrm{MPa}$. It can be seen that the $10 \%$ and $12 \%$ SBA admixed specimens were somewhat meeting the requirement according to BIS standards. Hence it can be easily concluded that $10 \%$ addition of SBA gives good results.

It could be observed that the compressive strength of $20 \%$ cement stabilized soil blocks admixed without SBA is $7.29 \mathrm{~N} / \mathrm{mm}^{2}$ and the addition of SBA in the case of $10 \%$ cement stabilized blocks results in a steady increase in compressive strength of the stabilized blocks. If we compare compressive strength of $10 \%$ addition of SBA and $10 \%$ cement stabilized block 
Sustainability, Agri, Food and Environmental Research, (ISSN: 0719-3726), 10(X), 2022:

http://dx.doi.org/

with $20 \%$ of cement there is an increment from 2.58 MPa to 7.29 MPa. Khobklang .reported strengths of 7.68 MPa and 7.66 MPa at 28 days of curing for two different water/binder ratios adopted in making of their cement stabilized lateritic soil-sand interlocking blocks with SBA. These blocks had a cement to SBA ratio of $15 \%$. The reported strength values are comparatively higher with respect to the present study. However, it needs to be mentioned that the calculated cement contents from the mix proportions were slightly higher than those in the present study. And also, sand was used as aggregate along with soil $(1: 1 \mathrm{mix})$ in manufacture of the blocks. Greepala \&. Parichartpreecha (2011) reported compressive strengths as high as $11.7 \mathrm{MPa}$ for a cement to SBA ratio of $10 \%$ for stabilized lateritic soil interlocking blocks with sand. It is clearly observed that the strength gain is higher due to addition of SBA at higher cement content. For $80 \%$ soil and $20 \%$ cement the compressive strength obtained is 7.29 MPa. For $10 \%$ SBA addition to $10 \%$ cement stabilized blocks and $80 \%$ of soil, there is strength of $2.58 \mathrm{MPa}$ whereas on further increasing the SBA that means $12 \%$ SBA content there is strength gain of $1.02 \mathrm{MPa}$ and for $14 \%$ SBA addition and $6 \%$ cement, strength reduced to 0. $65 \mathrm{MPa}$. In comparison, the addition of SBA to $10 \%$ cement stabilized soil blocks gives good results compared to $8 \%$ cement and $12 \%$ SBA. However, addition of $10 \%$ SBA to $10 \%$ cement stabilized blocks raises the block strength to meet the minimum requirements of standard blocks, whereas $10 \%$ cement stabilized block does not require SBA addition to meet the criteria despite SBA addition giving strength benefit. Thus, $12 \%$ SBA addition can reduce cement content from $10 \%$ to $8 \%$ for manufacture of stabilized soil blocks that does not meets the standards. Salim et.al 2004, in his study he reported a percentage strength gain is as high as $65 \%$ for compressed earth block stabilized with $10 \%$ SBA alone. The huge difference in percent strength gain in comparison with the present study may be due to the fact that strength of cement stabilized block without SBA is used as reference for calculation of percentage strength gain in the present study. In the work done by (Salim,et.al, 2004), percentage strength gains are based on strength of unstabilized soil block. 
Sustainability, Agri, Food and Environmental Research, (ISSN: 0719-3726), 10(X), 2022:

http://dx.doi.org/

Table 3. Compressive strength of different combinations of soil, cement and sba

\begin{tabular}{|c|c|c|c|c|}
\hline Sr. No. & Load (kn) & Area $\left(\mathrm{mm}^{2}\right)$ & Strength $\left(\mathrm{n} / \mathrm{mm}^{2}\right)$ & Average $\left(\mathrm{n} / \mathrm{mm}^{2}\right)$ \\
\hline 1 & 20 & 150 & 0.89 & 0.95 \\
\hline \multirow[t]{5}{*}{ (100\% Soil) } & \multicolumn{3}{|c|}{$x 150$} & \\
\hline & 24.4 & 150 & 1.08 & \\
\hline & \multicolumn{2}{|r|}{$x 150$} & & \\
\hline & 20 & 150 & 0.89 & \\
\hline & \multicolumn{2}{|r|}{$x 150$} & & \\
\hline 2 & 160.6 & 150 & 7.14 & 7.29 \\
\hline (80\% Soil & \multicolumn{2}{|r|}{$x 150$} & & \\
\hline \multirow[t]{3}{*}{ 20\% Cement) } & 171.5 & 150 & 7.62 & \\
\hline & \multicolumn{2}{|r|}{$x 150$} & & \\
\hline & 160 & 150 & 7.11 & \\
\hline \multicolumn{4}{|c|}{$x 150$} & \\
\hline 3 & 58.5 & 150 & 2.6 & 2.58 \\
\hline (80\% Soil & \multicolumn{2}{|r|}{$x 150$} & & \\
\hline $10 \%$ Cement & 58 & 150 & 2.57 & \\
\hline \multirow[t]{2}{*}{$10 \%$ SBA) } & \multicolumn{2}{|r|}{$x 150$} & & \\
\hline & 58 & 150 & 2.57 & \\
\hline \multicolumn{4}{|c|}{$x 150$} & \\
\hline 4 & 24 & 150 & 1.066 & 1.018 \\
\hline (80\% Soil & \multicolumn{2}{|r|}{$x 150$} & & \\
\hline $8 \%$ Cement & 22.8 & 150 & 1.0133 & \\
\hline \multirow[t]{2}{*}{$12 \%$ SBA) } & \multicolumn{2}{|r|}{$x 150$} & & \\
\hline & 22 & 150 & 0.977 & \\
\hline & \multicolumn{2}{|r|}{$x 150$} & & \\
\hline 5 & 14.4 & 150 & 0.64 & 0.6543 \\
\hline (80\% Soil & \multicolumn{2}{|r|}{$x 150$} & & \\
\hline $6 \%$ Cement & 14.8 & 150 & 0.657 & \\
\hline \multirow[t]{3}{*}{$14 \%$ SBA) } & \multicolumn{2}{|r|}{$x 150$} & & \\
\hline & 15 & 150 & 0.666 & \\
\hline & \multicolumn{2}{|r|}{$x 150$} & & \\
\hline
\end{tabular}


Sustainability, Agri, Food and Environmental Research, (ISSN: 0719-3726), 10(X), 2022: http://dx.doi.org/

Some earlier literature has been collected and reported the research adopting combinations of cement and SBA. The two investigations in particularly, done by Lima et al. (2012) and Greepala \&. Parichartpreecha (2011), were found to be similar to the present study in terms of stabilizer additive combination with enough data for making a comparison. The differences in the investigation done by Lima et al., (2012) include a granular soil type, higher cement content, slightly different SBA contents, and slightly denser blocks. The differences in the work done by Lima et al., (2012) and include the soil type (lateritic), use of sand as aggregate, varying cement and SBA contents, and slightly lighter blocks. However, this comparison still does not account for the difference in soil type since according to Adam (Adam et. al, 2001) the compressive strength of a stabilized block depends upon soil type, type and amount of stabilizer, and compaction pressure used to form the block. The work reported by Lima et al., (2012) develops the highest compressive strength. However, the increasing addition of SBA results in a drastic drop in the compressive strength. Despite the reduced compressive strength, it is still the strongest of all the blocks compared. The reduction in strength may be attributed to the reducing cement content in the mix as Lima et al., (2012) have adopted SBA as a replacement for cement in their study. Nevertheless, it may be possible that higher cement content adopted in the investigation may also be an added reason for reduced effectiveness of SBA. This can be inferred from the steep drop in strength till a stabilizer content ratio of 0.43 corresponding to a cement content of $10 \%$. On further increase in SBA content and corresponding decrease in cement content, the slope of the curve flattens in comparison, indicating SBA to be effective at higher cement content. A complex combination of the two reasons may be responsible for the drastic reduction in strength with increased SBA content. The comparison reveals the effects of difference in soil types and addition of sand as aggregate. It also reinforces the fact that SBA is effective in raising the strength at higher cement content.

\section{CONCLUSION}

The study involved the utilization of combination of cement and SBA in the manufacture of stabilized soil blocks and gauges its performance with plain cement stabilized blocks as well as the minimum requirements stipulated by BIS code. Based on the results of the experimental investigation carried out, the following points can be concluded. (i) Cement stabilization of locally available soil can be used in the manufacture of stabilized soil blocks to meet the compressive strength norms of BIS specifications. (ii) Addition of SBA to cement in stabilization results in an increased compressive strength of the blocks. However, SBA addition is more effective at higher cement content of $10 \%$ producing higher strength gains 
Sustainability, Agri, Food and Environmental Research, (ISSN: 0719-3726), 10(X), 2022:

http://dx.doi.org/

when compared to cement content of $8 \%$ and $6 \%$. iv) Addition of $12 \%$ SBA to $8 \%$ cement content slightly decreases its compressive strength to meet the strength requirements. $(v)$ The compressive strength of $6 \%$ cement with $14 \%$ SBA is not enough to meet block specifications. Hence, in order to achieve a higher safety margin, slightly higher contents of SBA and cement combinations can be investigated to arrive at optimum combinations from the point of view of cost and performance. (vi) The durability aspect of the cement stabilized blocks has not been investigated in this study. Hence, it is recommended that the durability aspect of cement stabilized blocks admixed with SBA should be taken up in future investigations.

\section{REFERENCES}

Adam, E.A., and Agib, A.R.A., 2001. Compressed stabilized earth block manufacture in Sudan. United Nations Educational, Scientific and Cultural Organization, Paris, France.

Balakrishnan, M., and V.S. Batra, 2011. Valorization of solid waste in sugar factories with possible applications in India: a review. Journal of Environmental Management, 92: 2886-2891.

BIS, 1982. Specification for soil-based blocks used in general building construction. IS 1725, 1982.

Ganesan, K., K. Rajagopala, K. Thangavelb, 2007. Evaluation of bagasse ash as supplementary cementitious material," Science Direct by Elsevier.

Greepala V., and R. Parichartpreecha, 2011. Effects of using flyash, rice husk ash and bagasse ash as replacement materials on the compressive strength and water absorption of lateritic soil-cement interlocking blocks: In Proceedings of the 9th Australasian Masonry Conference, pp. 583-603, Queenstown, New Zealand.

Halid A., S. Nagapan, A., Antonyova, K., Rasiah, R., Yunus, S. Sohu, 2017. Comparison of strength between laterite soil and clay compressed stabilized earth bricks. MATEC web of conferences.

Jijo J., P. Kasinatha Pandian, K. Deepika, J. Manikanda Venkatesh, V. Manikandan, and P. Manikumaran, 2016. Cement stabilized soil blocks admixed with sugarcane bagasse ash. ISSN 0974-5904, International Journal of Earth Sciences and Engineering, Volume 06, No.01.

Khobklang, P., K. Nokkaew, and V. Greepala, 2008. Effect of bagasse ash on water absorption and compressive strength of lateritic soil interlocking block. In Proceedings of the International Conference on Excellence in Concrete Construction Through Innovation. 
Sustainability, Agri, Food and Environmental Research, (ISSN: 0719-3726), 10(X), 2022:

http://dx.doi.org/

Lima, S.A., H. Varum, A. Sales, and V.F. Neto, 2012. Analysis of the mechanical properties of compressed earth block masonry using the sugarcane bagasse ash. Construction and Building Materials, 35: 829-837.

Mangesh, V., Madurwar, A. Sachin, A., Mandavgane and V. Rahul Ralegaonkar, 2014. Use of sugarcane bagasse ash as brick material. Current Science, 107, No.6, Research Communication.

Onchiri, R., J. Kiprotich, B. Sabuni, C. Busieney 2014. Use of sugarcane bagasse ash as a partial replacement for cement in stabilization of self-interlocking earth blocks. International Journal of Civil Engineering and Technology (IJCIET).

Qing Xu, Tao Ji, San-Ji Gao, Zhengxian Yang, and Nengsen Wu, 2019. Characteristics and applications of sugar cane bagasse ash waste in cementitious materials. Materials, 12 , 39, 2019, doi:10.3390/ma12010039.

Salim, R.W., J.M. Ndambuki, and D.A. Adedokun, 2014. Improving the bearing strength of sandy loam soil compressed earth block bricks using sugercane bagasse ash. Sustainability, 6: 3686-3696.

Sabat, A.K. 2012. Utilization of bagasse ash and lime sludge for construction of flexible pavements in expansive soil areas. Electronic Journal of Geotechnical Engineering. 17:1037-1046

Sales and S.A. Lima, 2010.Use of Brazilian sugarcane bagasse ash in concrete as sand replacement. Waste Management 30: 1114-1122.

Sua-iam, G., and N. Makul, 2013. Use of increasing amounts of bagasse ash waste to produce self-compacting concrete by adding limestone powder waste. Journal of Cleaner Production, 57: 308-319.

Received: $15^{\text {th }}$ February 2021; Accepted: 04 ${ }^{\text {th }}$ May 2021; First distributed: 04 ${ }^{\text {th }}$ May 2021 